\title{
Experimental research of gold migration influenced by cyclic flooding-drainage of rock mass
}

\author{
Vitaly Taganov ${ }^{1 *}$, Kirill Gevalo ${ }^{1}$ and Ekaterina Alekseeva ${ }^{1}$ \\ ${ }^{1}$ Mining Institute FEB RAS, 51 Turgenev st., Khabarovsk, 680000, Russia
}

\begin{abstract}
Efficient development of man-made placers is subject to the introduction of new technological solutions, as well as implementing the possibility of choosing the optimal design and technological indicators of mining and processing equipment, depending on the combination of influencing natural, design and technological factors. The most important research goal is the invention of new innovative technologies. To solve these problems, the direction of research on the development and theoretical substantiation of geotechnology for the development of technogenic alluvial deposits was determined and is being developed on the basis of the intra-dump concentration of valuable components, which ensures the formation of an enriched zone in the near-bed area. In order to develop the technology, the authors carried out large-scale theoretical and experimental studies to study the nature and degree of influence of a number of factors that form the basis of the technology on the migration and concentration of gold particles in the man-made rock mass, as well as determining the technological parameters and modes of flooding and drainage of the rock mass.
\end{abstract}

\section{Introduction}

Nowadays, the explored reserves of alluvial gold mining are steadily depleting. This is caused by significant reduction in geological exploration, which previously provided a constant increase in reserves at operating facilities and the involvement of new ones. In this regard, the role of technogenic alluvial deposits increases, since their involvement in operation does not require large capital expenditures. However, the development of such deposits is often unprofitable due to the low gold content, as well as the increased content of small size and fine-grained gold, for the extraction of which special beneficiation methods are required [1-10]. Therefore, an important scientific and technological task is to substantiate an effective technology for the development of technogenic placers as a reserve of the raw material base of placer gold mining.

Based on the technogenic alluvial formations study by scientists of the Institute of Mining of the Far Eastern Branch of the Russian Academy of Sciences, the phenomenon of intra-dump concentration was established, where, under the influence of predominantly

*Corresponding author: taganov11@gmail.com 
natural factors, high density particles move in the vertical direction - migrate, and concentrate in the lower horizons of the massif.

These factors include the following processes: hydrodynamic, including filtration and suffusion; cryogenic; microseismic. Their influence on efficiency, intensity and, in general, on the formation of technogenic placers of a new type differ, therefore, the authors carried out large-scale theoretical and experimental studies to study the nature and degree of influence of these factors on the processes of migration and concentration of metal particles with a high density in the technogenic rock mass [11 - 14].

\section{Experimental research}

Cyclic freezing and thawing of rocks is accompanied by diverse and complex thermophysical, physicochemical and physicomechanical processes, which lead to significant transformations of their material composition, structure, texture and properties [15]. The influence of cyclic freezing-thawing on the behavior of dispersed material has been studied by many Soviet and foreign scientists, but most of them were aimed at studying changes in the properties of rocks and further usefulness of these changes. During cyclic freezing and thawing of dispersed rocks, a redistribution of particles occurs, in which the densest particles move downward - migrate. The fact of gold grain migration is confirmed by experiments carried out in the laboratory of the Institute of Mining of FEB RAS $[11-14,16]$, the result of which revealed the following:

— fine grades gold migrates best (size of $-0.25 \mathrm{~mm}$ );

- the depth of gold migration increases with an increase in the number of freezing and thawing cycles;

- cryogenic processes as an independent factor have an insignificant effect on the migration of gold particles, and the main influencing factor is the presence of a filtration flow.

Experimental laboratory studies have shown that under the complex influence of external factors on the rock mass, the distribution of gold over the thickness of the rock sample proceeded most efficiently, the migration of gold into the underlying layers increased from $20 \%$ when exposed only to the filtration flow to $64.3 \%$ with two additional freezing and thawing cycles; the lower layer reached the fraction $-0.1 \mathrm{~mm}$, and with the complex impact it is $19 \%$ more [11].

As a result of industrial experimental studies carried out at Bolotistiy spring placer deposit (Khabarovsk Territory) for two years, it was possible to form an enriched layer (with a content above $125 \mathrm{mg} / \mathrm{t}$ ), the volume of which is $44 \%$ of the total volume of sand in the experimental unit [12].

Further experimental studies have revealed that the process of migration of gold particles occurs more efficiently under the cyclical effect of the filtration flow, when the technogenic sand unit is flooded and drained according to a certain time dependence. We have studied the effect of several cycles of flooding and drainage of rock mass on the value of gold migration [16]: 1.5 days of constant water supply, 2 days of drainage; 2.2 days of water supply, 1 day of drainage; 3.1 day of water supply, 1 day of dehumidification; 4. Flooding with incomplete drainage (water supply resumed until complete drainage); 5. 2 minutes of water supply, 8 minutes of drainage; 6.5 minutes of flooding, 5 minutes of drainage; 7.8 minutes of flooding, 2 minutes of drainage.

The gold migrated most efficiently during cycle 4 (the gold content in the lower layers increased by $23.2 \%$ relative to the initial one) and during cycle 6 (the gold content in the bottom layer of the $-0.5+0.2 \mathrm{~mm}$ fraction increased by $28 \%$ relative to the initial one, the $0.2+0.1 \mathrm{~mm}$ fraction - by $87 \%$ ). 
The maximum intensity of changes in the gold content with depth $\mathrm{I}=0.313$ was observed in the study of cycle 6 ; then, according to the obtained equation, $\mathrm{k}=0.55$, i.e. the flooding time should be $55 \%$ of the total cycle time. Additional experimental studies are needed to confirm the data obtained.

In 2019 , in order to clarify the previously obtained results, laboratory experimental studies of the study of the migration of gold particles in the technogenic rock mass under the influence of a cyclic filtration flow were continued. The experiment lasted 6 months.

The result of sample enrichment is shown as the graph at Fig. 1, which additionally depicts straight lines obtained as a result of regression analysis.

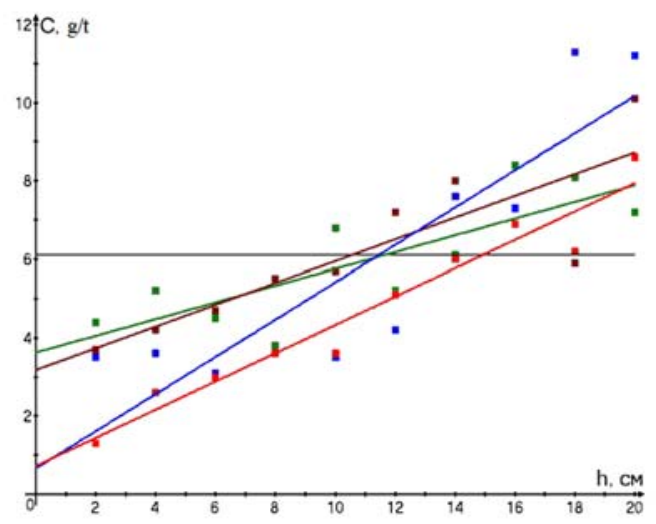

Fig. 1. The gold content in samples

$\square, \mathbf{\square}, \mathbf{\square}, \mathbf{-}$ - gold content in samples in containers 1, 2, 3, 4 relatively; - regression equation for the change in content in container $1, \mathrm{k}_{\mathrm{u}}=0,88\left(\mathrm{k}_{\mathrm{\kappa op}}=0,65\right)$; - regression equation for the change in content in container $2, \mathrm{k}_{\mathrm{u}}=0,51\left(\mathrm{k}_{\mathrm{Kop}}=0,75\right)$; - regression equation for the change in content in container $3, \mathrm{k}_{\mathrm{L}}=0,35\left(\mathrm{k}_{\text {кор }}=0,79\right)$; - regression equation for the change in content in container $4, \mathrm{k}_{\mathrm{L}}=0,17\left(\mathrm{k}_{\text {кор }}=0,95\right)$; - initial content

The data analysis made it possible to obtain a multifactorial dependence $\mathrm{C}=\mathrm{f}(\mathrm{k} \iota, \mathrm{h})$, represented by a multiple regression equation of a quadratic form $\left(\mathrm{k}_{\text {кор }}=0,88\right)$, which shows that an increase in gold content occurs at all values of the cycle index kц:

$$
\mathrm{C}=-0,208+9,467 \cdot \mathrm{k} ц+0,305 \cdot \mathrm{h}-4,203 \cdot \mathrm{k} ц 2+0,010 \cdot \mathrm{h} 2-0,393 \cdot \mathrm{k} \mu \mathrm{h},
$$

where $\mathrm{C}$ - gold content, $\mathrm{mg} / \mathrm{t} ; \mathrm{k}_{\mathrm{u}}$ - cycle factor; $\mathrm{h}-$ depth, $\mathrm{cm}$.

The experimental data analysis showed that gold particles migrated in all containers.

In container $1(\mathrm{k} \amalg=0.88)$, the change in gold content with depth occurred to a greater extent due to the fraction $-1.0+0.5 \mathrm{~mm}$, as well as the fraction $-0.2+0.1 \mathrm{~mm}$, the content of which in the upper half decreased, and at the bottom - increased by $10 \%$. The average gold content of all fractions in the top 5 layers decreased, and in the bottom 5 layers increased by $14 \%$ relative to the initial one.

In container $2(\mathrm{k} ц=0.51)$ the average gold content of all fractions in the lower half increased by $21 \%$ relative to the initial one. It is worth noting a significant change in the gold content of the $-0.2+0.1 \mathrm{~mm}$ fraction - the amount of gold of this fraction decreased in the upper five layers and increased in the lower five by $16 \%$.

In container $3(\mathrm{k} \amalg=0.35)$, the largest increase in the average gold content of all fractions is observed in the lower half of the experimental sand block - by $37.8 \%$. Migration mainly affected gold particles of the fraction $-1.0+0.2 \mathrm{~mm}$; migration of gold with a particle size of $-0.2+0.1 \mathrm{~mm}$ is insignificant.

In container $4(\mathrm{k} \mu=0.17)$, the increase in the average gold content in the five lower layers was $24.2 \%$, mainly due to the fraction $-1.0+0.5 \mathrm{~mm}$. A change in the gold content of the $0.2+0.1 \mathrm{~mm}$ fraction is noted, however, the amount of migration is not sufficient to reach this fraction of the lower horizons of the experimental unit, which can be explained by the short duration of the filtration flow. 
The experimental data analysis lead us to the conclusion that the migration process most effectively took place in the container 3 with $\mathrm{k} \mu=0.35$, however, the increase in gold content is associated, to a greater extent, with a change in the content of the fraction $-1.0+$ $0.5 \mathrm{~mm}$, and migration of the fine gold $(0.2+0.1 \mathrm{~mm})$ is less significant. In container 2 with $\mathrm{k} \mu=0.51$, the greatest increase in the gold content of the fraction $-0.2+0.1 \mathrm{~mm}$ is noted. Thus, the parameters of the optimal freezing-thawing cycle of the rock mass have an intermediate value between the parameters of the cycles organized in containers 2 and 3 with a cycle coefficient of 0.51 and 0.35 , respectively.

\section{Technological parameters validation}

The studies carried out make it possible to validate the technology for the development of man-made alluvial deposits with the formation of enriched zones, which consists in the following [13]: in the upper and lower parts of the block of man-made sands, which is evenly planned in terms of thickness, there are water-supply and accumulation ditches, respectively, after which a certain amount of technological water introduced, sufficient for the formation of a filtration flow in the technogenic block and capable of displacing fine particles of host rocks in the thickness of the sands and carrying them out to other areas. Water consumption is calculated by the developed method depending on the filtration properties of the sands and the sieve characteristics of gold [11]. The resulting additional volumes of pore space provide the ability to move high density particles mainly in the vertical direction - migration. With prolonged exposure to such a flow, an enriched sand layer is formed in the near-bed part of the block, which is characterized by a homogeneous structure, a relatively small volume of productive rock mass. This makes it possible to separate sands with a low gold content, to significantly reduce the volume of washing and to develop the technogenic placer with greater profitability.

The geometrical parameters of the prepared sand block are determined by specific mining and geological conditions and depend on the following factors [13]:

- terrain and slope of the valley. The sand block to be prepared must be positioned so that the direction of the filtration flow coincides with the slope of the valley, i.e. there was a pressure between the water supply and storage ditches, the minimum value of which should ensure the formation of a stable filtration flow;

- granulometric composition of the rock mass. One of the factors limiting the application of the technology is the high content of silt-clay fractions that clog pore tubes and impede the movement of particles. The studies made previously have established that almost all sands of technogenic placer deposits have suffusion properties, which is an important positive factor in the technology of formation of enriched zones of technogenic placers [17];

- mining and geological conditions of the natural placer;

- remoteness of the source of process water and its debit, etc.

With an average placer width of up to $80-100 \mathrm{~m}$ and a planned effel stockpile thickness of up to $2 \mathrm{~m}$, the length of the prepared block should be at least $750 \mathrm{~m}$ (subject to the preparation of a sand block with a volume of 150 thousand $\mathrm{m}^{3}$ ). With such a block length, large hydraulic resistances are observed, in the presence of which the filtration rate and filtration flow rate decrease with increasing block length even with increasing pressure [13]. To prepare a block of this length, it is necessary to pass several intermediate ditches after $100-150 \mathrm{~m}$ (depending on the sand filtration coefficient) along the entire width, dividing the block into several subblocks. In this case, the accumulation ditch of the upper sub-block will be the water supply ditch for the underlying one. 
The structure of the man-made placer depends on a number of factors as follows: the method of primary development of the deposit, the frequency of development, natural mining and geological conditions and technical and economic factors. The composition of the mining preparatory work of the developed technology depends on the method of primary development during the development of the whole part of the placer, which includes the following technological processes: de-forestation (if any), removing the pebble dump outside the prepared block (except for the inter-way sinuses during the primary dredging mining the placer), planned lixiviation stockpile on an even basis in terms of capacity within the primary working, ditching, water supply, formation of a filtration flow.

The described technology provides for the removal of a pebble dump over the entire area of the mined site in the first year, making of waterworks, accumulating and intermediate ditches, supplying water to the ditches, creating a stable filtration flow, the flow of which is calculated according to the developed method, and the beginning of the stage of forming an enriched layer. The enriched layer is considered to be formed when the gold content in it reaches the required value corresponding to modern economic requirements, which is determined by the results of enrichment of the samples taken in layers [13, 18]. Industrial experimental studies carried out show that it is possible to form an enriched sand layer with a volume of 2 or more times less than the initial one in 2-3 leaching seasons.

At the next stage, sands with a low (non-industrial) gold content are collected or stored, and the formed enriched layer is washed on a washing device with a developed beneficiation scheme, which ensures high recovery of small size and fine-grained gold.

\section{Conclusion}

The study revealed that technogenic alluvial deposits are often not involved in mining due to the low metal content, as well as the presence of a large amount of small-size and finegrained gold. For the profitable development of such deposits, technology has been developed and experimentally and theoretically substantiated, based on the use of the ability of gold particles to migrate to the near-bedrock part of the placer under the influence of natural processes, which will make it possible to form an enriched layer of sands with a content equal to or exceeding the industrial one. The proposed technology will make it possible to efficiently develop technogenic alluvial deposits of precious metals, as well as to start developing placers, the exploitation of which was previously considered economically unsound.

\section{References}

1. V.S. Litvintsev, V.S. Alekseev, I.A. Kradenykh, V.I. Usikov, Mine survey and subsurface use, 5, 21-29 (2017)

2. V.S. Litvintsev, Physical and technical problems of the development of useful minerals, 1, 97 - $104(2015)$

3. V.S. Litvintsev, T.S. Banshchikova, N.A. Leonenko, Physical and technical problems of mineral resources development, 1, 190 - 194 (2012)

4. V.S. Litvintsev, R.S. Seryi, T.S. Banshchikova, P.P. Sas, Physical and technical problems of the development of useful minerals, 2, 72 - 79 (2016)

5. I.Y. Rasskazov, N.G. Shkabarnya, V.S. Litvintsev, G.N. Shkabarnya, Eurasian Mining, 2, 3 - 7 (2017) DOI: 10.17580 / em.2017.02.01

6. G.S. Mirzekhanov, V.S. Litvintsev, Journal of mining, 10, $25-30$ (2018) DOI: 10.17580 / gzh.2018.10.04 
7. G.S. Mirzekhanov, Z.G. Mirzekhanova, Resource potential of technogenic formations of placer gold deposits: Monograph (M.: MAKS Press, 2013)

8. D.A. Vnukov, F.S. Kotov, Gold and technology, 3, 52 - 54 (2011)

9. R.S. Seryi, Mine survey and subsoil use. Publishing house Geomar Nedra, 6, 20-22 (2014)

10. R.S. Seryi, V.V. Taganov, K.V. Gevalo, Journal of mining, 10, 49 - 52 (2018) DOI: 10.17580 / gzh.2018.10.09.

11. V.S. Alekseev, R.S. Seryi, Physical and technical problems of the development of useful minerals, 3, 110 - 115 (2016)

12. V.S. Alekseev, P.P. Sas, R.S. Seryi, Physical and technical problems of the development of useful minerals, 6, 191 - 197 (2017) DOI: 10.15372 / FTPRPI20170620.

13. V.S. Alekseev, Substantiation of a rational technology for the formation of a productive zone in the open-cut mining of technogenic placers in the Amur region: author's abstract... PhD (Khabarovsk, 2012)

14. Yu.A. Mamaev, V.S. Litvintsev, V.S. Alekseev, News of higher educational institutions. Journal of mining, 8, 135-145 (2011)

15. A.S. Kurilko, Experimental studies of cyclic freezing-thawing on the physicochemical properties of rocks, Ed. V.A. Sherstov; Institute of Mining of the North SB RAS (Yakutsk: YaP Publishing house SB RAS, 2004)

16. V. Alekseev, T. Banshchikova, E3S Web of Conferences, 56 (2018) DOI: 10.1051 / e3sconf / 20185603023

17. V.S. Litvintsev, V.S. Alekseev, A.M. Pulyaevsky, Physical and technical problems of the development of mineral resourses, 5, 157 - 163 (2012)

18. V.S. Litvintsev, V.S. Alekseev, V.V. Taganov, Patent 2712880 RF, IPC E21C 41/30. Method of formation of enriched zones of technogenic placer by cyclic impact of filtration flow; declared 06/25/2019; publ. 31.01.2020 